\title{
Teaching cultural aspects of psychiatry
}

\author{
Margreet Peutz
}

This paper discusses a pllot teaching programme on cultural aspects of psychiatry undertaken as part of the academic programme of the Department of Psychiatry, Cambridge University. The aim of the programme was to stimulate thinking about psychiatric phenomena in a different, more culturally aware perspective. Feedback was collected from participants through an evaluation questionnaire following the series. More practical and experiential teaching of cultural psychiatry is needed.

In recent years, interest in 'culture' within British psychiatry has been increasing steadily. In March 1990 a special issue of the British Journal of Psychiatry on cross-cultural psychiatry was published and in April 1992 the Transcultural Psychiatry Special Interest Group of the Royal College of Psychiatrists was inaugurated. The guidelines for the MRCPsych examination mention explicitly that candidates shall be examined on their knowledge or awareness of cultural variation in social concepts, groups and institutions (Royal College of Psychiatrists, 1987).

In 1993, the academic programme in Cambridge offered trainees teaching in the social sciences, but it was lacking in lectures or seminars that focused specifically on cultural aspects of psychiatry. At that time, I was aware of only a few isolated initiatives on teaching social anthropology in relation to psychiatry in the UK, namely in London and in Birmingham (Lloyd et al, 1991). Working as a senior registrar in Cambridge and having previously studied social anthropology. I decided to undertake a teaching initiative in this area.

\section{Teaching programme in Cambridge}

The teaching programme consisted of three lectures on social anthropology for the regional MRCPsych course, and four seminars on cultural psychiatry as part of the wider academic programme. Overall, the teaching of cultural psychiatry made up $2.5 \%$ of the academic programme in 1993.

The lectures for the MRCPsych course explained the nature of social anthropology, the development of the discipline, and its fields of study at present. It described the characteristics of the anthropological approach, with its concern with meaning rather than measurement, its holistic view, its attempts to grasp the broader contexts and frameworks within which people behave and experience (Peacock, 1986), and its emphasis on comparative work. The course elaborated on its particular research methodology, namely participant observation and ethnographic interviews. Some video material on kinship structures in different cultures and on faith healing was presented and finally, issues in cultural psychiatry were reviewed.

The seminars on cultural psychiatry took place in the summer term of 1993. In the first seminar the scope of anthropology, its development and general characteristics were reviewed, followed by a discussion of anthropologically informed research within psychiatry. An example was the development of culture-sensitive questionnaires such as dealt with by Inge-Britt Krause in her study of the Punjabi idiom of distress and the development of an appropriate General Health Questionnaire (Krause, 1989). The subsequent seminars were given by guest lecturers. The first guest lecturer spoke about the psychological effects of war and violence in the Third World, based on his experience in Uganda. The second lecturer, an Asian-trained psychiatrist doing research in London, talked about his work on depression among the English, offering an Asian perspective on this familiar topic. The last guest lecturer, a child psychiatrist, presented a crosscultural perspective on child sexual abuse.

\section{Evaluation of the programme}

Overall, attendance was very low. Only seven of the 20 junior doctors registered for the MRCPsych course attended the lectures. A total of 15 people, out of the whole staff complement of the psychiatric department and Fulbourn Hospital, attended one, rarely more, of the seminars (average of four per seminar).

By means of an evaluation questionnaire, sent subsequently to those who attended, feedback on the lectures and seminars was received. Most said they were interesting and relevant, and comments were made such as "(it) . . . introduced 
thinking about issues that need more thought inside and outside psychiatry". The video clips were generally welcomed. Most reported having been confronted with cultural or cross-cultural issues in their psychiatric practice, but very few had ever received any teaching in cultural psychiatry. All felt there was a need for specific teaching in the form of lectures on theoretical aspects, seminars, and clinical case presentations. A greater emphasis on clinical examples and clinical management was asked for. Some suggestions for gaining relevant experience were made, for example, by means of discussions with colleagues of different cultural backgrounds, or, more creatively, by spending a weekend with a family of a different ethnic group.

\section{Discussion}

The general aim was to stimulate thinking about psychiatric phenomena in a different, more culturally aware perspective. The distinguishing feature of the discipline of anthropology is no longer its exotic subject matter, but rather its particular perspective and research methods brought to bear on the study of any cultural group, including one's own. In my opinion, an anthropological approach in psychiatric research and practice can strengthen our discipline by sharpening its sensitivity to culture, and help avoid the traps of ethnocentricity. The question remains as to which form of teaching would best promote this.

From the discussions that took place during this pilot programme in Cambridge, it seemed that participants who had been exposed more intensively to a different culture, i.e. psychiatrists from ethnic minorities in the UK or from abroad (India, Japan, Canada), or who had worked for an extended period in a different culture in the past, were most aware of the issue of culture in relation to psychiatry. A recent report in the Psychiatric Bulletin of a trainee's experience of psychiatry in a developing country corroborates this observation (McCutcheon, 1995). The general call for more clinical case discussions, as well as the wish of some to directly experience life in another culture, indicate that participants felt a need to be exposed to cultural psychiatry in a more practical and experiential way.

In order to be really meaningful the teaching of cultural psychiatry needs to be primarily experiential. In our multi-cultural society, this should be relatively easy to arrange in at least one way.
All trainees are likely to be involved with patients from cultural backgrounds different from their own. Therefore, as part of their training, they might be expected to make a detailed study of at least one case, to read relevant articles on social anthropology and cultural psychiatry and to write up the case, with particular reference to its cultural ramifications. Supervision would best be provided, when available, by psychiatrists with a special interest in cultural psychiatry, both during the treatment and the writing-up phase. Appropriate reading material could be drawn from the College's reading lists, although the section on Transcultural Psychiatry is in need of expansion. Supervisors could suggest additional articles or books of particular relevance to each individual case.

The College acknowledges that "transcultural psychiatry is an important element in the education of psychiatrists" (Royal College of Psychiatrists, 1990). The Calman Report recommended close definition of training programmes and their syllabuses (DoH, 1993). If Calman is followed, an opportunity presents itself to raise the profile of cultural psychiatry by including appropriate training in the curriculum.

\section{References}

DEPARTMENT OF HEALTH (1993) Hospital Doctors: Training for the Future. The Report of the Working Group on Specialist Medical Training (Calman Report). London: HMSO.

KraUSE, I.-B. (1989) Sinking heart: a Punjabi communication of distress. Social Science and Medicine, 29, 563-575.

LLOYD, K. PEZEShGI, S. \& HODES, M. (1991) Teaching social anthropology in relation to psychiatry. Psychiatric Bulletin, 15, 422-423.

MCCUTCHEON, R. (1995) Are psychiatry attachments in developing countries for the British trainee useful? Psychiatric Bulletin, 18, 161-162.

PEACOCK, J. L. (1986) The Anthropological Lens: Harsh Light, Soft Focus. Cambridge: Cambridge Untversity Press.

ROYAL COLLEGE OF PSYCHIATRISTS (1987) General Information and Regulations for the MRCPsych Examination. London: Greenaway Harrison.

- (1990) Statement by Council on Psychiatric Practice and Training in British mult-ethnic society. Psychiatric Bulletin, 14, 432-437.

Margreet Peutz, Staff Psychiatrist, South Shore Regional Hospital, Bridgewater, Nova Scotia. Canada

Correspondence: R.R.\#2, Mahone Bay, Nova Scotia, Canada BOJ 2EO 